\title{
Lens-induced glaucoma in the elderly
}

REVIEW

This article was published in the following Dove Press journal:

Clinical Interventions in Aging

23 July 2009

Number of times this article has been viewed

\section{Dimitris Papaconstantinou \\ Ilias Georgalas \\ Nikos Kourtis \\ Augustine Krassas \\ Andreas Diagourtas \\ Chrysanthi Koutsandrea \\ Gerasimos Georgopoulos}

Department of Ophthalmology,

University of Athens, Athens, Greece
Correspondence: Dimitris Papaconstantinou

Consultant Ophthalmic Surgeon,

Mesogeion Ave, Athens, Greece

Email dpapaconstantinou@hotmail.com

\begin{abstract}
Lens-induced glaucoma comprises a number of different glaucomatous processes occurring in the elderly that share in common the role of the crystalline lens in the mechanism of increase in intraocular pressure. We will review the anatomic predisposing factors, their physiology, signs and symptoms, and therapeutic approach. We will consider two studies and discuss the visual results and risk factors associated with these pathologic conditions.
\end{abstract}

Keywords: glaucoma, intraocular pressure

\section{Introduction}

Lens-induced glaucoma in the elderly can be subdivided into two major categories. The first category relates to a blockage of the anterior flow of the aqueous humor from the lens that results in an increase of intraocular pressure (IOP). Conditions included in this category are: (1) pupillary block glaucoma caused by an intumescent cataractous lens (phacomorphic glaucoma), (2) ectopia lentis. The second category is characterized by the blockage of the trabecular meshwork from lens proteins (phacolytic glaucoma), lens material or debris, and rarely by phacoanaphylactic response to lens material.

\section{Pupillary block glaucoma}

This type of glaucoma is characterized by the obstruction of the aqueous outflow by the apposition of the iris root to the trabecular meshwork. Eyes which develop angle-closure glaucoma secondary to pupillary block have been observed to have several predisposing anatomic factors. The most important factor is a shallow anterior chamber. The depth of the chamber is dependent on the dimensions of the lens, the cornea, and the axial length of the globe. With aging, the lens assumes greater thickness, a greater curve of its anterior surface, and the zonules loosen. ${ }^{1-4}$ These factors cause increasing shallowness of the anterior chamber and iridolenticular contact, ${ }^{5}$ which results in a greater amount of pupillary block. ${ }^{3}$ As a consequence, hyperopic eyes have a propensity for pupillary block.

The physiology of angle-closure glaucoma is as follows. There are two muscles in the iris: the sphincter and the dilator. During mid-dilation, the posterior component of the dilator's force reaches a maximum. ${ }^{7-9}$ If this force becomes strong enough to overcome the anterior component of the dilator's force, then the iris is pushed against the lens and a pupillary block will ensue. This will obstruct the aqueous flow from the posterior to the anterior chamber. The aqueous will accumulate in the posterior chamber, which pushes the iris forward and finally the iris root will come in contact 
with the trabecular meshwork and lead to angle-closure glaucoma. This mechanism is facilitated by the anatomic predisposing factors that were mentioned previously.

A senile cataractous lens that has progressed enough to become intumescent, has an increased anteroposterior length, which could lead to pupillary block. This type of glaucoma is named phacomorphic (Figure 1).

Phacomorphic glaucoma often occurs from a mature cataract, but may also occur from spherophakia in Weill-Marchesani syndrome. Phacomorphic glaucoma could present asymptomatically as chronic angle-closure glaucoma, however it more often presents as acute angleclosure glaucoma. Acute angle-closure glaucoma will cause a significant increase in IOP, which is characterized by ocular pain, headache, blurred vision, perception of halos around lights (due to the corneal edema), and also nausea, vomiting, bradycardia, and diaphoresis due to the vasovagal response. Symptoms usually occur at night because mid-dilation predisposes relative pupillary block.

The clinical examination reveals reduced visual acuity secondary to corneal edema, conjuctival injection, a mid-dilated pupil, and, in the case of phacomorphic glaucoma, an intumescent cataractous lens which pushes the iris forward and reduces the depth of the anterior chamber peripherally. The latter also shows cells and flare. The fellow eye shows the same anatomic predisposing factors and probably a cataract (phacomorphic). ${ }^{10}$

Treatment focuses on two objectives: lower the IOP as soon as possible and prevent the diseased and fellow eye from another episode. ${ }^{11}$

Initially, IOP-lowering medications are used. Topical beta blockers, carbonic anhydrase inhibitors, and hyperosmotic

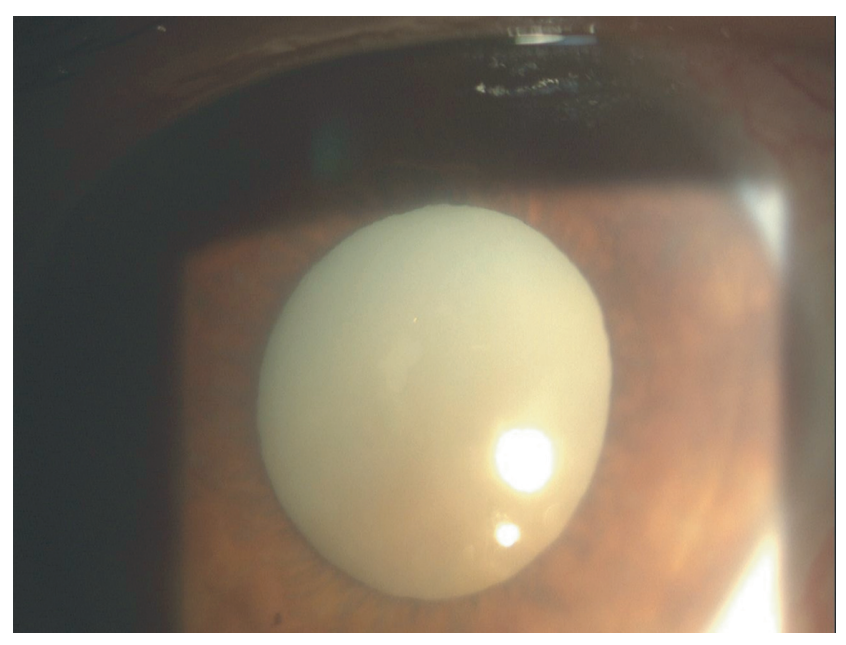

Figure I Hypermature cataractous lens. agents (mannitol IV) are the mainstay of medical treatment. Parasympathomimetic agents (pilocarpine $1 \%$ or $2 \%$ ) tend to increase pupillary block, so they should be used with caution. ${ }^{12}$ When this approach fails to lower IOP, then some other methods can be recruited: corneal depression with a Zeiss 4-mirror lens, iridectomy with the Nd:YAG laser, gonioplasty with an argon laser, coreoplasty with an argon laser, and application of digital massage. ${ }^{11,13,14}$ If the fellow eye is also anatomically predisposed to angleclosure glaucoma, prophylactic laser iridotomy should be performed.

In the case of phacomorphic glaucoma, after IOP control and establishing intraocular inflammation, we proceed to cataract extraction, which erases the major causative factor of angle-closure glaucoma.

\section{Ectopia lentis}

This clinical entity may present as an isolated inherited form such as ectopia lentis and ectopia lentis et pupillae. Ectopia lentis may also be associated with systemic disorders such as Marfan's syndrome, homocystinuria, Weill-Marchesani syndrome, hyperlysinemia, and sulfite oxidase deficiency. The biochemical defects in these conditions result in defective zonular apparatus and subluxation/dislocation of the lens often occurs (Figures 2, 3).

Dislocation of the crystalline lens may be secondary to trauma. ${ }^{15}$

Symptoms vary according to the individual state of the lens. Minimal subluxation may be asymptomatic. Progressive disruption of the zonules allows the lens to assume a more spherical shape, which results in increasing degrees of myopia. If the lens is shifted within the pupillary axis, then

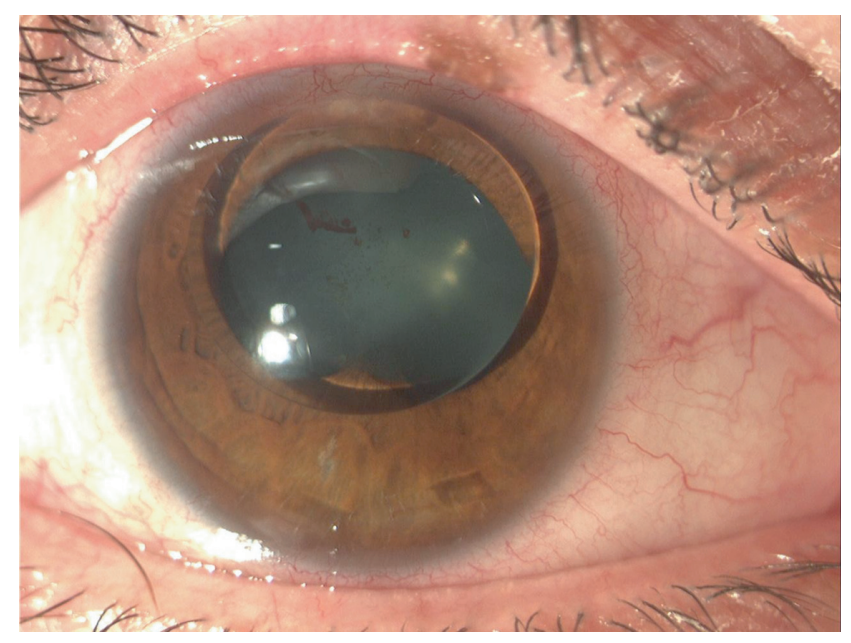

Figure 2 Ectopia lentis. 


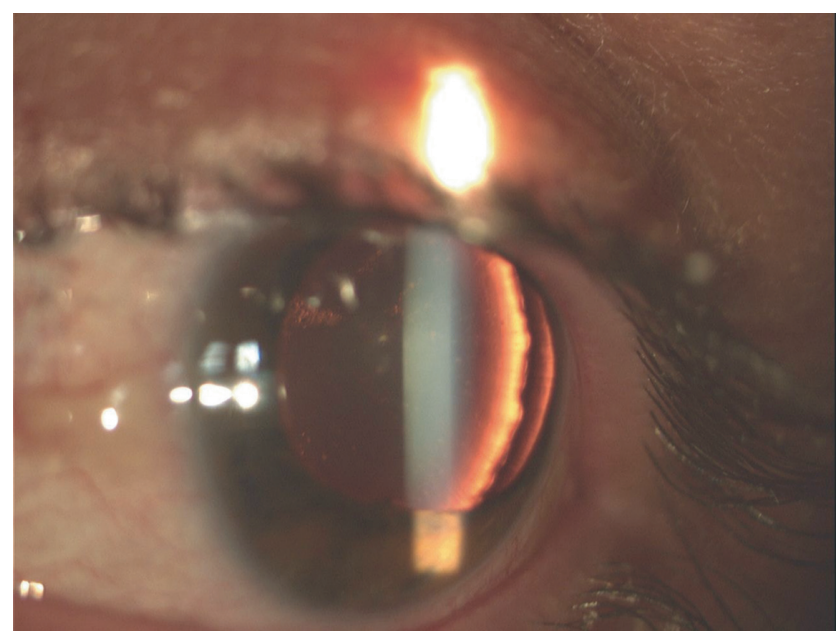

Figure 3 Post-traumatic lens dislocation.

monocular diplopia may ensue. The loss of zonular support results in difficulties with accommodation and near vision. Complete dislocation from the pupillary axis renders the patient hyperopic because of an aphakic optical condition. When dislocation results in pupillary block and angle-closure glaucoma is present, the patient experiences a red and painful eye, decreased visual acuity, and sometimes headache, nausea, and vomiting.

Signs include phacodonesis, iridodonesis, shallowing of the anterior chamber either symmetrically or asymmetrically, and a difference in the depth of the anterior chamber between the two eyes. Gonioscopically, the iris may be seen to assume the shape of a volcano with the pupil forming the central crater. This is the result of the anterior movement of the lens and increased contact with the middle third of the iris.

The therapeutic approach depends on the degree of dislocation and the symptoms. In cases of partial subluxation within the pupillary space that does not cause significant visual impairment or pupillary block glaucoma, a conservative nonintervention strategy could be followed. When the previous condition is accompanied by pupillary block, then a laser peripheral iridectomy is the appropriate solution. Total anterior dislocation requires removal of the lens. Dislocation in the vitreous cavity may be followed carefully as long as the cataract is not hypermature and no inflammation or glaucoma is noticed. If any of these factors are present, removal of the lens is indicated.

Ciliary block (malignant) glaucoma sometimes may be confused with phacomorphic glaucoma in cases where the anterior chamber is too shallow. However, malignant glaucoma in its classic form occurs after surgery for glaucoma and is characterized by the misdirection of aqueous fluid into the vitreous cavity. ${ }^{16-31}$

\section{Phacolytic glaucoma}

This acute open-angle glaucoma is the result of the leakage of lenticular material from senile hypermature or Morgagnian cataract through an intact lens capsule (Figure 4). The presentation is a red and painful eye, history of gradual decline of visual acuity reflecting the slow maturation of the cataract, corneal edema, high IOP, an open-angle in gonioscopy, a heavy flare, and aqueous cells larger than the lymphocytes seen in uveitis. These cells are thought to be macrophages swollen with eosinophilic lenticular material which they have engulfed. ${ }^{32}$ Soft white patches on the lens capsule can be observed, which are aggregates of macrophages trying to seal the site of leakage. ${ }^{33}$ The fellow eye usually has a mature cataract and a deep anterior chamber.

The original theory about the pathogenesis of this condition was that the macrophages were the major culprit of increase in IOP by blocking the trabecular meshwork. ${ }^{33,34}$ Later research by Epstein and colleagues, ${ }^{35}$ Yanoff and Scheie, ${ }^{32}$ and Dueker ${ }^{36}$ emphasized the role of heavy molecular proteins (HMW) leaking from the lens in the obstruction of the aqueous outflow and de-emphasized the role of the macrophages. As a consequence, the examination of the anterior chamber fluid for the presence of HMW protein has become an important diagnostic aid in suspected and atypical cases of phacolytic glaucoma, but is not yet widely available.

The majority of patients with phacolytic glaucoma can be managed through topical cycloplegia, topical steroids, and

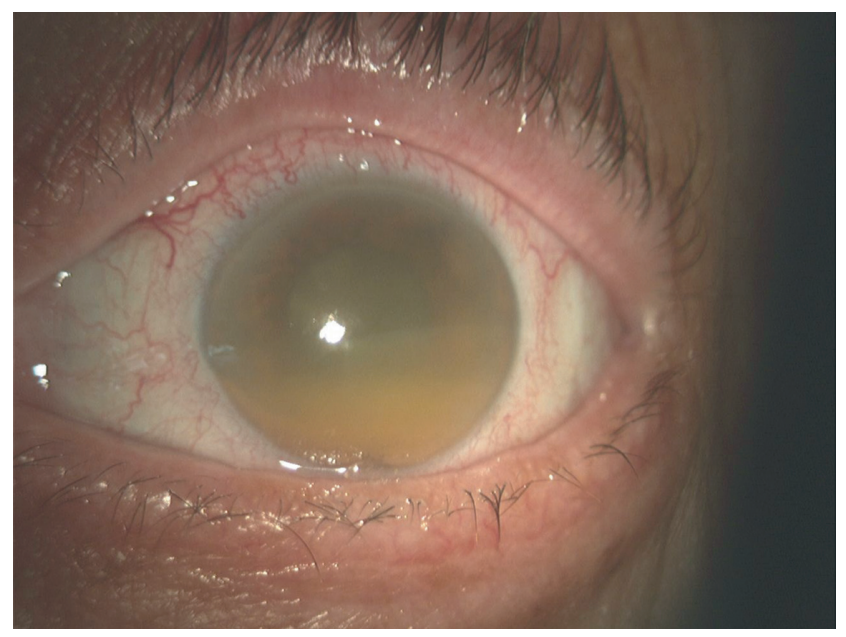

Figure 4 Lens proteins in the anterior chamber, phacolytic glaucoma. ${ }^{3}$ 
aqueous suppressants. If despite intensive antiglaucomatous therapy, IOP continues to increase, emergency admission may be advocated, and in rare instances urgent cataract or vitreoretinal surgery may be required. ${ }^{37-41}$

\section{Lens-particle glaucoma}

In contrast to phacolytic glaucoma, this form of lens-induced glaucoma is associated with a grossly disrupted capsule and the presence of obvious fragments of lens material in the anterior chamber. It may occur after cataract surgery, trauma to the lens, or Nd:YAG posterior capsulotomy. The IOP increase is due to the obstruction of the aqueous outflow by the lens particles. ${ }^{32}$ Despite the presence of macrophages as scavengers of the lens material, their role in the pathogenesis of the glaucoma is not significant.

Initially, a trial of medical antiglaucomatous therapy may be attempted, but miotics should be avoided. Mild to moderate steroid therapy can help to prevent synechiae, pupillary membranes, cystoid macular edema, etc. If the glaucoma is severe and/or there is a large amount of lens material in the anterior chamber, its surgical removal should be undertaken.

\section{Phacoanaphylactic glaucoma}

Phacoanaphylactic glaucoma is an inflammatory reaction directed against lenticular antigens with elevation of the IOP due to involvement of the trabecular meshwork by the inflammation or by obstruction from inflammatory cells. A less usual mechanism is the formation of synechiae resulting in pupillary block.

The series of events leading to the IOP rise is as follows: the patient is sensitized to his own lens antigens and these proteins are kept in an immunologically privileged site within the lens capsule. After an eye surgery or other trauma to the lens capsule, these lens antigens are exposed to the circulation, they may be recognized as 'foreign' by the individual's immune system and they incite an inflammatory response. A matter not completely elucidated is why some patients develop this reaction and others do not.

The time interval between the trauma and the onset of inflammation is 24 hours to 14 days. The clinical signs include lid edema, chemosis, conjuctival injection, corneal edema, heavy anterior chamber reaction, posterior synechiae, and mutton fat keratic precipitates.

Pathologically, a granulomatous reaction is noted with polymorphonuclear, epithelioid, and giant cells surrounding lenticular material. Phacoanaphylaxis is not the correct name of this condition since it is not an allergy. Eosinophils may be found but not immunoglobulin E (IgE). The mechanism causing the reaction seems to be an Arthus-type immune complex reaction mediated by $\operatorname{IgG}$ and the complement system. ${ }^{42,43}$ In the past, the differentiation between phacoanaphylaxis and sympathetic ophthalmia was confusing, but once it is understood that the former involves only the anterior segment of the eye, the diagnosis is easy. ${ }^{44,45}$

The first step in therapy is the effort to control the IOP and inflammation medically. If this proves unsuccessful then the next phase is surgical removal of the remaining lens material. ${ }^{46}$

\section{Epidemiology: prognostic factors}

There are two studies from the Indian Journal of Ophthalmology that investigate lens-induced glaucomas, more specifically phacomorphic and phacolytic glaucomas.

The first study ${ }^{47}$ deals with the clinical modes of presentation, the postoperative visual results, and the risk factors that relate to the visual outcome of such cases. The percentage of phacomorphic glaucomas $(52.7 \%)$ is slightly higher than phacolytic (47.3\%) and the latter is more common with increasing age probably due to aggregation of high molecular weight proteins in the crystalline lens over time. After surgical management with extracapsular cataract extraction, $57 \%$ of phacomorphic and $61 \%$ of phacolytic cases had good visual acuity (6/12 or better) and $10.2 \%$ of phacomorphic and $13.6 \%$ of phacolytic cases had poor visual recovery (6/60 or less). The conclusion in this study was that there was no statistically significant difference between the two groups on the final postoperative visual recovery. When they investigated the risk factors they found a statistically marginally significant increased risk $(p=0.05)$ of females having these glaucomas. Also, males had a slightly higher risk of obtaining poor postoperative visual acuity (odds ratio $[\mathrm{OR}]=2.2 ; 95 \%$ confidence interval $[\mathrm{CI}]$ : 0.88-5.66), but this statement has to be analyzed with caution, because the mean age of males was higher than the females and age may be a confounding factor. A significant risk of poor visual acuity was found when the duration between the onset of pain and surgery exceeded five days (OR $=3.1 ; 95 \%$ CI: 1.21-8.13). Marginally significant risk of poor visual outcome was observed in cases of age higher than 60 years when compared with younger patients. Finally, between the level of preoperative IOP and final visual acuity, no significant association was found $(\mathrm{p}=0.07)$.

The second study ${ }^{48}$ dealt with the frequency and types of lens-induced glaucoma, the reasons for late presentation, and the outcome of current management. The percentage of 
phacomorphic glaucomas was higher in this study (72\%) than the phacolytic (28\%). A similar result occurred in relation to gender since the ratio of females:males was $1.7: 1$. The comparison between the two studies is difficult when we look at the visual results because the groups are different. In the latter study, $38.6 \%$ achieved a visual acuity of $6 / 60$ or better, $31.2 \%$ less than $6 / 60$, and $30.2 \%$ less than $3 / 60$. In the phacolytic group, $65.9 \%$ had a poor outcome compared with $59.8 \%$ of the phacomorphic group. This poor outcome was associated in the latter group with a longer distance from the hospital, longer duration of pain, and higher IOP at presentation. In the phacolytic group, only the distance was found to influence negatively the visual outcome. In this series, the final visual outcome is worse than in other studies, probably because the majority of the patients reported later than ten days after the onset of pain.

In conclusion, lens-induced glaucoma comprises a number of different glaucomatous processes occurring in the elderly that share in common the role of the crystalline lens in the mechanism of increase in IOP. Early diagnosis and treatment of mature cataract is very important since delayed treatment of lens-induced glaucoma may result in poor visual outcome.

\section{Disclosure}

The authors report no conflicts of interest in this work.

\section{References}

1. Lowe R. Causes of shallow anterior chamber in primary angle-closure glaucoma. Am J Ophthalmol. 1969;67:87-93.

2. Lowe R. Anterior lens displacement with age. $\mathrm{Br} J$ Ophthalmol. 1970;54:117-121.

3. Lowe R. Aetiology of the anatomical basis for primary angle-closure glaucoma. Br J Ophthalmol. 1970;54:161-169.

4. Markowitz S, Morin D. Angle-closure glaucoma: relation between lens thickness, anterior chamber depth and age. Can J Ophthalmol. 1984;19:300-302.

5. Fontana S, Brubaker R. Volume and depth of the anterior chamber in the normal aging human eye. Arch Ophthalmol. 1980;98: 1803-1808.

6. Epstein DL. Diagnosis and management of lens-induced glaucoma. Ophthalmology. 1982;89:229-230.

7. Mapstone R. Closed-angle glaucoma: Theoretical considerations. Br J Ophthalmol. 1974;58:36-40.

8. Mapstone R. Angle closure mechanisms in glaucoma. Semin Ophthalmol. 1986;1:35-40.

9. Mapstone R. Acute shallowing of the anterior chamber. $\mathrm{Br} J$ Ophthalmol. 1981;65:446-451.

10. Spalton DJ, Hitchings RA, Hunter PA. Atlas of Clinical Ophthalmology. Philadelphia, PA: JB Lippincott and Co; 1984.

11. Hoskins HD, Kass M. Becker-Shaffer's Diagnosis and Therapy of the Glaucomas. 6th Ed. St. Louis, MO: CV Mosby Co; 1989.

12. Kramer P, Ritch R. The treatment of acute angle-closure glaucoma revisited. Ann Ophthalmol. 1984;16,1101-1103.

13. Ritch R. Argon laser treatment for medically unresponsive attacks of angle-closure glaucoma. Am J Ophthalmol. 1982;94:197-204.
14. Koster HR, Liebmann JM, Ritch R, Hudock S. Acute angle-closure glaucoma in a patient with acquired immunodeficiency syndrome successfully treated with argon laser peripheral iridoplasty. Ophthalmic Surg. 1990;21:501-502.

15. Georgopoulos GT, Papaconstantinou D, Georgalas I, Koutsandrea CN, Margetis I, Moschos MM. Management of large traumatic zonular dialysis with phacoemulsification and IOL implantation using the capsular tension ring. Acta Ophthalmol Scand. 2007;85:653-657.

16. Simmons R. Malignant glaucoma. Br J Ophthalmol. 1972;56: 263-272.

17. Hardten DR, Brown JD. Malignant glaucoma after Nd:YAG cyclophotocoagulation. Am J Ophthalmol. 1991;111:245-247.

18. Weiss IS, Dieter PD. Malignant glaucoma syndrome following retinal detachment surgery. Ann Ophthalmol. 1974;6:1099-1104.

19. DiSclafani M, Liebmann JM, Ritch R. Malignant glaucoma following argon laser release of scleral flap sutures after trabeculectomy. Am J Ophthalmol. 1989;108:597-598.

20. Robinson A, Prialnic M, Deutsch D, Savir H. The onset of malignant glaucoma after prophylactic laser iridotomy. Am J Ophthalmol. 1990;110:95-96.

21. Levene RZ. Current concepts of malignant glaucoma. Ophthalmic Surg. 1986; 17:515-520.

22. Levene R. A new concept of malignant glaucoma. Arch Ophthalmol. 1972;87:497-506.

23. Phelps CD. Angle-closure glaucoma secondary to ciliary body swelling. Arch Ophthalmol. 1974;92:287-290.

24. Weiss DI, Shaffer RN. Ciliary block (malignant) glaucoma. Trans Am Acad Ophthalmol Otolaryngol. 1972;76:450-461.

25. Epstein DL. Experimental perfusions through the anterior chamber and vitreous with possible relationships to malignant glaucoma. Am J Ophthalmol. 1979;88:1078-1086.

26. Ellant JP, Obstbaum SA. Lens-induced glaucoma. Doc Ophthalmol. 1992;81:317-338.

27. Chandler PA, Grant WM. Mydriatic-cycloplegic therapy in malignant glaucoma. Arch Ophthalmol. 1962;68:353-359.

28. Herschler J. Laser shrinkage of the ciliary processes. Ophthalmology. 1990;87:1155-1158.

29. Chandler PA. A new operation for malignant glaucoma: a preliminary report. Trans Am Ophthalmol Soc. 1964;62:408-424.

30. Chandler PA, Simmons RJ, Grant WM. Malignant glaucoma. Medical and surgical treatment. Am J Ophthalmol. 1968;66:495-502.

31. Momoeda S, Hayashi H, Oshima K. Anterior pars plana vitrectomy for malignant glaucoma. Jpn J Ophthalmol. 1983;27:73-79.

32. Yanoff M, Scheie HG. Cytology of human lens aspirate. Its relationship to phacolytic glaucoma and phacoanaphylactic endophthalmitis. Arch Ophthalmol. 1968;80:166-170.

33. Flocks M, Littwin CS, Zimmerman LE. Phacolytic glaucoma: a clinicopathological study of 138 cases of glaucoma associated with hypermature cataract. Arch Ophthalmol. 1955;54:37-45.

34. Irvine SR, Irvine AR Jr. Lens-induced uveitis and glaucoma. I. Endophthalmitis phaco-anaphylactica. Am J Ophthalmol. 1952;35: 177-186.

35. Epstein DL, Jedziniak J, Grant WM. Identification of heavy molecular weight soluble protein in aqueous humor in human phacolytic glaucoma. Invest Ophthalmol Vis Sci. 1978;17:398-402.

36. Feder RS, Dueker DK. Can macrophages cause obstruction to aqueous outflow in rabbits? Int Ophthalmol. 1984;7(2):87-93.

37. Izzotti A, Sacca SC, Longobardi M, Cartiglia C. Sensitivity of ocular anterior-chamber tissues to oxidative damage and its relevance to glaucoma pathogenesis. Invest Ophthalmol Vis Sci. 2009; Jun 10. [Epub ahead of print]

38. Dada T, Kumar S, Gadia R, Aggarwal A, Gupta V, Sihota R. Sutureless single-port transconjunctival pars plana limited vitrectomy combined with phacoemulsification for management of phacomorphic glaucoma. J Cataract Refract Surg. 2007;33:951-954.

39. Chu ER, Durkin SR, Keembiyage RD, Nathan F, Raymond G. Nineteenyear delayed-onset phacolytic uveitis following dislocation of the crystalline lens. Can J Ophthalmol. 2009;44:112. 
40. Venkatesh R, Tan CS, Kumar TT, Ravindran RD. Safety and efficacy of manual small incision cataract surgery for phacolytic glaucoma. Br J Ophthalmol. 2007;91:279-281.

41. Rossiter JD, Morris AH, Etchells DE, Crick MP. Vitrectomy for phacolytic glaucoma in a patient with ectopia lentis et pupillae. Eye. 2003;17(2):243-244.

42. Thach AB, Marak GE Jr, McLean IW, Green WR. Phacoanaphylactic endophthalmitis: a clinicopathologic review. Int Ophthalmol. 1991;15:271-279.

43. Marak GE, Font RL, Alepa FP. Experimental lens-induced granulomatous endophthalmitis. Mod Probl Ophthalmol. 1976;16: $75-79$.
44. Allen JC. Sympathetic uveitis and phacoanaphylaxis. Am J Ophthalmol. 1967;63:280-283.

45. Easom HA, Zimmerman LE. Sympathetic ophthalmia and bilateral phacoanaphylaxis. Arch Ophthalmol. 1964;72:9-15.

46. Riise P. Endophthalmitis phacoanaphylactica. Am J Ophthalmol. 1965;60:911-915.

47. Prajna RV, Ramakrishnan R, Krishnadas R, Manoharan N. Lens-induced glaucomas-visual results and risk factors for final visual acuity. Indian J Ophthalmol. 1996;44:149-155.

48. Pradhan D, Hennig A, Kumar J, Foster A. A prospective study of 413 cases of lens-induced glaucoma in Nepal. Indian J Ophthalmol. 2001;49:103-107.

\section{Publish your work in this journal}

Clinical Interventions in Aging is an international, peer-reviewed journal focusing on evidence-based reports on the value or lack thereof of treatments intended to prevent or delay the onset of maladaptive correlates of aging in human beings. This journal is indexed on PubMed Central, MedLine, the American Chemical Society's 'Chemical
Abstracts Service' (CAS), Scopus and the Elsevier Bibliographic databases. The manuscript management system is completely online and includes a very quick and fair peer-review system, which is all easy to use. Visit http://www.dovepress.com/testimonials.php to read real quotes from published authors.

Submit your manuscript here: http://www.dovepress.com/clinical-interventions-in-aging-journal 